Plasma-enhanced atomic layer deposition of vanadium phosphate as a lithium-ion battery electrode material

Thomas Dobbelaere and Felix MattelaerPhilippe M. VereeckenChristophe Detavernier

Citation: Journal of Vacuum Science \& Technology A: Vacuum, Surfaces, and Films 35, 041513 (2017); doi: 10.1116/1.4987131

View online: http://dx.doi.org/10.1116/1.4987131

View Table of Contents: http://avs.scitation.org/toc/jva/35/4

Published by the American Vacuum Society

Contact Hiden Analytical for further details: W www.HidenAnalytical.com E info@hiden.co.uk CLICK TO VIEW our product catalogue

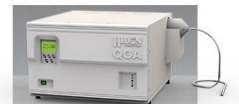

Gas Analysis - dynamic measurement of reaction gas streams cataysis and thermal analysis , molecular bean studes , dissolved speces probes , fermentation, envirormental and ecological studis

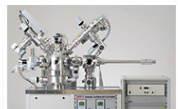

Surface Science

UHVTPD
SIMS

, end point detection in in beam etch , elemental imaging-surface mapping

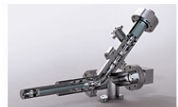

Plasma Diagnostics plasma source characterization etch and deposition process reaction kinetic studies

analysis of neutral and radical species

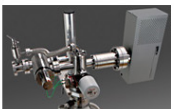

Vacuum Analysis partial pressure measurement and control of process gases reactive sputter process control vacuum diagnostic 


\title{
Plasma-enhanced atomic layer deposition of vanadium phosphate as a lithium-ion battery electrode material
}

\author{
Thomas Dobbelaere and Felix Mattelaer \\ Department of Solid State Sciences, Ghent University, Krijgslaan 281 S1, 9000 Gent, Belgium \\ Philippe M. Vereecken \\ imec, Kapeldreef 75, 3001 Leuven, Belgium and Department of Microbial and Molecular Systems, \\ Centre for Surface Chemistry and Catalysis, University of Leuven, Celestijnenlaan 200F, \\ 3001 Leuven, Belgium \\ Christophe Detavernier $^{\mathrm{a})}$ \\ Department of Solid State Sciences, Ghent University, Krijgslaan 281 S1, 9000 Gent, Belgium
}

(Received 10 April 2017; accepted 8 June 2017; published 20 June 2017)

\begin{abstract}
Vanadium phosphate films were deposited by a new process consisting of sequential exposures to trimethyl phosphate (TMP) plasma, $\mathrm{O}_{2}$ plasma, and either vanadium oxytriisopropoxide [VTIP, $\left.\mathrm{OV}(\mathrm{O}-\mathrm{i}-\mathrm{Pr})_{3}\right]_{\text {or }}$ tetrakisethylmethylamido vanadium [TEMAV, $\left.\mathrm{V}(\mathrm{NEtMe})_{4}\right]$ as the vanadium precursor. At a substrate temperature of $300^{\circ} \mathrm{C}$, the decomposition behavior of these precursors could not be neglected; while VTIP decomposed and thus yielded a plasma-enhanced chemical vapor deposition process, the author found that the decomposition of the TEMAV precursor was inhibited by the preceding TMP plasma $/ \mathrm{O}_{2}$ plasma exposures. The TEMAV process showed linear growth, saturating behavior, and yielded uniform and smooth films; as such, it was regarded as a plasma-enhanced atomic layer deposition process. The resulting films had an elastic recoil detection-measured stoichiometry of $\mathrm{V}_{1.1} \mathrm{PO}_{4.3}$ with $3 \%$ hydrogen and no detectable carbon contamination. They could be electrochemically lithiated and showed desirable properties as lithiumion battery electrodes in the potential region between 1.4 and $3.6 \mathrm{~V}$ versus $\mathrm{Li}^{+} / \mathrm{Li}$, including low capacity fading and an excellent rate capability. In a wider potential region, they showed a remarkably high capacity (equivalent to three lithium ions per vanadium atom), at the expense of reduced cyclability. @ 2017 American Vacuum Society. [http://dx.doi.org/10.1116/1.4987131]
\end{abstract}

\section{INTRODUCTION}

Atomic layer deposition (ALD) is a thin film deposition method, which grows material on a surface by exposing it to alternating chemical precursor vapors. In contrast to chemical vapor deposition (CVD), the precursors are introduced separately, with pumping or purging steps in between them. This causes self-limiting reactions to take place on the substrate surface, resulting in layer-by-layer film growth. The advantages of ALD over CVD include better step coverage (enabling the conformal coating of 3D structures), lower temperature deposition (enabling deposition on temperaturesensitive substrates), and insensitivity to process variations (in a saturated regime, the growth rate is inherently constant, even when the precursor exposure varies). ${ }^{1}$ This comes at the expense of very slow growth (typically in the order of $1 \AA$ /cycle), making ALD most suitable for very thin films. Although many different ALD processes have been developed for various classes of materials such as oxides, ii-vi and iii-v semiconductors, metal nitrides, metals, metal sulfides, and fluorides, ${ }^{2}$ the existing reports on ALD of phosphates are still limited, ${ }^{3-13}$ but have recently been increasing in number because of their relevance as electrode ${ }^{14-18}$ or electrolyte ${ }^{19-22}$ films in lithium-ion batteries.

Various forms of vanadium oxide $\left(\mathrm{VO}_{x}\right)$ can be grown using existing, well-characterized ALD processes based on, e.g.,

${ }^{a)}$ Electronic mail: christophe.detavernier@ugent.be vanadium oxytriisopropoxide $\left[\text { VTIP, } \mathrm{OV}(\mathrm{O}-\mathrm{i}-\mathrm{Pr})_{3}\right]^{23}$ or tetrakisethylmethylamido vanadium $\left[\mathrm{TEMAV}, \mathrm{V}(\mathrm{NEtMe})_{4}\right]^{24,25}$ as the vanadium precursor. To our knowledge, ALD of vanadium phosphate has not been attempted before. The most closely related work is perhaps a recent report by Strempel et al., wherein a submonolayer of phosphorus was deposited on the surface of $\mathrm{V}_{2} \mathrm{O}_{5}$ powder in order to modify its catalytic properties. $^{26}$ However, no "bulk" vanadium phosphate was synthesized.

In addition to its applications in catalysis, vanadium phosphate finds use as a lithium-ion battery electrode material. In its lithiated, monoclinic crystalline form, $\mathrm{Li}_{3} \mathrm{~V}_{2}\left(\mathrm{PO}_{4}\right)_{3}$ is known as a high-energy, high-power (i.e., high rate performance) cathode material. ${ }^{27,28}$ Other forms are similarly active; in the amorphous state, it can be regarded as a $\mathrm{V}_{2} \mathrm{O}_{5^{-}}$ $\mathrm{P}_{2} \mathrm{O}_{5}$ (phosphovanadate) glass, which has been well studied already in the 1980s as a candidate electrode for lithium cells. ${ }^{29-31}$ Some authors have also explored the use of ( $\mathrm{Li}) \mathrm{V}(\mathrm{O}) \mathrm{PO}_{4}$ as a conversion-type anode material. ${ }^{32-34}$

In this study, we present a plasma-enhanced atomic layer deposition (PE-ALD) process for vanadium phosphate. We incorporate phosphorus by means of a trimethyl phosphate (TMP) plasma; we have previously used this method successfully for PE-ALD of aluminum phosphate, ${ }^{12}$ zinc phosphate,${ }^{13}$ iron phosphate, ${ }^{17}$ and titanium phosphate. ${ }^{18}$ Our plasma-enhanced method has the advantage of forming highly reactive phosphate species on the surface which easily react with a metalorganic precursor, typically resulting in 
high growth rates. The drawback is that the substrate temperature must be sufficiently high in order to inhibit any spontaneous polymerization of the TMP plasma, which results in an undesirable CVD contribution. ${ }^{12}$ This makes it more challenging to find a suitable metalorganic precursor; an insufficiently high decomposition temperature will result in thermal precursor decomposition and also yield an undesirable CVD contribution.

With this in mind, we start our experiments by investigating the decomposition behavior of two vanadium precursors, VTIP and TEMAV, in the phosphate process using in situ ellipsometry. Based on these results, we then develop and characterize a PE-ALD vanadium phosphate process and test the resulting material as a lithium-ion battery electrode.

\section{EXPERIMENT}

\section{A. Deposition system}

Depositions were carried out in a home-built pump-type PE-ALD reactor, shown schematically in Fig. 1. All parts were stainless steel, unless otherwise specified.

The deposition chamber was continuously evacuated by a turbomolecular pump to a base pressure of approximately $4 \times 10^{-6}$ mbar. Precursor vapors and gases were admitted through computer-controlled pneumatic valves. The TMP (Sigma-Aldrich, 97\%), VTIP (Sigma-Aldrich), and TEMAV (Air Liquide) precursor bottles were heated to resp. 45, 90, and $75^{\circ} \mathrm{C}$. TMP and VTIP were transported by their own vapor pressure (reaching approximately $5 \times 10^{-3}$ mbar in the deposition chamber), while TEMAV was carried by an argon flow. The argon and $\mathrm{O}_{2}$ gas supplies were adjusted to reach a pressure of $5 \times 10^{-3}$ mbar in the chamber. To avoid CVD side reactions, pumping times in between precursor exposures were chosen sufficiently long (approximately $20 \mathrm{~s}$ ) to bring residual pressures down to below $4 \times 10^{-5}$ mbar. The temperature of the chamber walls was set to

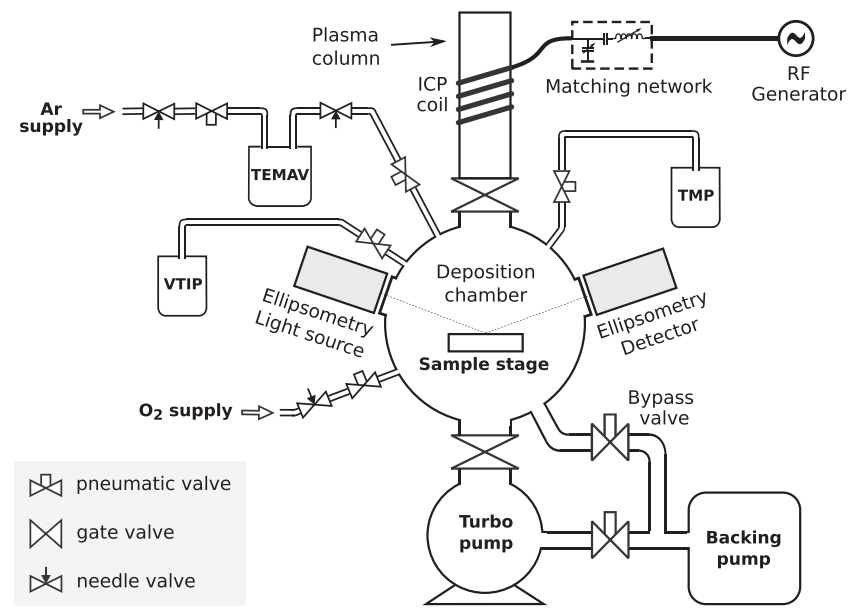

FIG. 1. Schematic drawing showing the essential components of the homebuilt PE-ALD setup used for all the depositions in this study, including the vacuum chamber along with its pumping system, the precursor connections, the inductively coupled plasma setup, and the in situ ellipsometry light source and detector. $130^{\circ} \mathrm{C}$, and all precursor tubes leading to the chamber were additionally heated to prevent any precursor condensation.

On top of the chamber, a gate valve led to a fused quartz column wrapped by a copper coil. The coil was connected to a $13.56 \mathrm{MHz}$ RF generator (ENI GHW-12Z) and a matching network in order to generate an inductively coupled plasma in the column. The remote plasma was generated by feeding vapor or gas from the chamber to the plasma column through the gate valve and pulsing the RF generator. The plasma power was set to $200 \mathrm{~W}$ for the TMP plasma and $300 \mathrm{~W}$ for the $\mathrm{O}_{2}$ plasma, and the impedance matching was tuned to minimize the reflected power on both. The substrates were mounted to a heated copper block, the temperature of which was proportional-integral-derivative-controlled. Depositions were performed on pieces of standard p-type silicon (100) wafer (for process characterization), or silicon wafer coated with platinum (for electrochemical characterization; the platinum coating functioned as a lithium ion diffusion barrier and as a current collector).

\section{B. Material characterization}

In situ spectroscopic ellipsometry measurements were performed with a J.A. Woollam M-2000 ellipsometer working in the ultraviolet-visible region and using the COMPLETEEASE software for fitting and data analysis. Measurements were acquired after each deposition cycle. Systematic parameters (angle offsets, window corrections) were fitted prior to deposition and then held fixed. The final thickness and the optical model parameters were fitted to the measurement acquired after the last cycle (i.e., after deposition). A growth curve was then obtained by fitting the thickness to each measurement, keeping all other parameters fixed. The final thicknesses were verified by $\mathrm{x}$-ray reflectometry (XRR) measurements acquired on a Bruker D8 diffractometer using $\mathrm{Cu} \mathrm{K} \alpha$ radiation. The XRR patterns were analyzed by fitting simulated patterns to the measured ones, yielding not only the film thickness but also the density. In situ $\mathrm{x}$-ray diffraction (XRD) during annealing was performed in a home-built setup. ${ }^{24,35,36}$ The annealing atmosphere was either helium or ambient air; the XRD patterns were acquired using a $\mathrm{Cu} \mathrm{K} \alpha \mathrm{x}$-ray source and a position sensitive detector. X-ray photoelectron spectroscopy (XPS) analysis was performed on a Thermo Scientific Theta Probe XPS instrument using $\mathrm{Al} \mathrm{K} \alpha \mathrm{x}$-rays generated at $15 \mathrm{kV}$ and $70 \mathrm{~W}$ and focused to a spot size of $0.3 \mathrm{~mm}$ by an MXR1 monochromator gun. To remove surface contamination, the sample surface was etched by $\mathrm{Ar}^{+}$ions at an acceleration voltage of $3 \mathrm{keV}$ and a current of $2 \mu \mathrm{A}$. Elastic recoil detection (ERD) measurements were carried out using an $8 \mathrm{MeV}^{35} \mathrm{Cl}^{4+}$ beam, with a scattering angle of $40^{\circ}$ and a sample tilt of $20^{\circ}$.

\section{Electrochemical testing}

Electrochemical test cells were constructed inside an argon-filled glovebox with $\mathrm{O}_{2}$ and $\mathrm{H}_{2} \mathrm{O}$ levels below $1 \mathrm{ppm}$. The working electrodes consisted of silicon substrates coated with PVD platinum (current collector) and then with PEALD vanadium phosphate (active material). The cells 
consisted of a polytetrafluoroethylene body filled with electrolyte ( $1 \mathrm{M} \mathrm{LiClO}_{4}$ in propylene carbonate) clamped against the working electrode, with the coated side facing the liquid, and sealed by a circular O-ring defining an electrode area of $1.05 \mathrm{~cm}^{2}$. All reported currents and charges were normalized against this footprint area, yielding units of $\mu \mathrm{A} / \mathrm{cm}^{2}$ (current) and $\mu \mathrm{Ah} / \mathrm{cm}^{2}$ (charge), respectively. An electrical contact was made by applying conductive silver ink on the cleaved sides of the substrate in order to connect the platinum current collector layer to a piece of copper foil. The counter electrode and reference electrode consisted of lithium metal, thereby measuring all working electrode potentials against $\mathrm{Li}^{+} / \mathrm{Li}$. The cyclic voltammetry and constant-current measurements were performed with home-built and commercial (Metrohm Autolab) potentiostat/galvanostat systems.

\section{RESULTS AND DISCUSSION}

\section{A. Decomposition experiments}

As mentioned in the Introduction, when using TMP plasma, a sufficiently high substrate temperature is required in order to inhibit the spontaneous plasma polymerization of TMP, which would result in PE-CVD instead of PE-ALD. Our previous studies using TMP plasma have established this temperature to be $300^{\circ} \mathrm{C} .{ }^{12,13,17,18}$ At this temperature, however, some metalorganic precursors will thermally decompose; this is also the case for our vanadium precursor candidates. From literature, the decomposition temperatures of VTIP and TEMAV are 200 and $175^{\circ} \mathrm{C}$, respectively, so one would expect strong thermal decomposition of both precursors at $300^{\circ} \mathrm{C}^{23-25}$

To test their decomposition behavior, we ran experiments where we pulsed the precursors into the chamber onto a silicon substrate heated to $300^{\circ} \mathrm{C}$, while using in situ ellipsometry to monitor film growth. When only the precursor is pulsed, any film growth is solely due to thermal decomposition. The result of doing this experiment with the VTIP precursor is shown in Fig. 2. Curve (a) initially consists of $2 \mathrm{~s}$ VTIP pulses, repeated for 50 cycles. Film growth is clearly

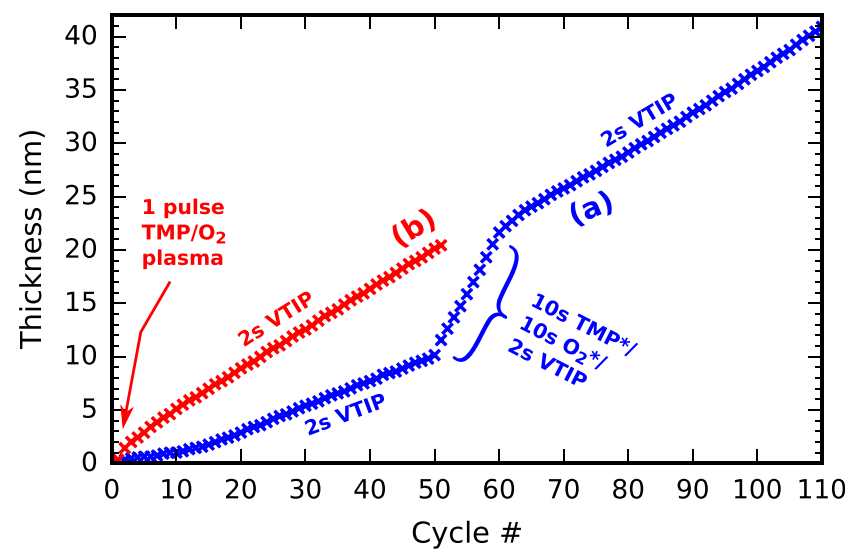

FIG. 2. (Color online) Decomposition tests with VTIP at a substrate temperature of $300^{\circ} \mathrm{C}$, showing the evolution of the deposited film thickness as a function of the cycle number for processes consisting of (a) $50 \times[2 \mathrm{~s}$ VTIP $]-10 \times\left[10 \mathrm{~s}\right.$ TMP plasma-10 $\mathrm{s} \mathrm{O}_{2}$ plasma-2 s VTIP $]-50 \times[2 \mathrm{~s}$ VTIP $]$ and (b) $1 \times\left[10 \mathrm{~s}\right.$ TMP plasma $-10 \mathrm{~s} \mathrm{O}_{2}$ plasma $]-50 \times[2 \mathrm{~s}$ VTIP $]$. observed, confirming that the precursor decomposes thermally; neglecting some initial nucleation delay, the growth is linear with a slope of $0.25 \mathrm{~nm} /$ cycle (it should be noted that this value is, of course, very dependent on the particular dosing conditions). When included in a vanadium phosphate process (consisting of TMP plasma, $\mathrm{O}_{2}$ plasma, and VTIP exposures, repeated for 10 cycles, using the same $2 \mathrm{~s}$ pulse duration of VTIP), linear growth is again observed, but at a significantly higher growth rate of $1.2 \mathrm{~nm} / \mathrm{cycle}$. This can be considered as PE-CVD of vanadium phosphate, with the CVD contribution originating from the thermal decomposition of VTIP. When the first pulse sequence (50 pulses of $2 \mathrm{~s}$ VTIP) is repeated after the 10-cycle phosphate process, thermal decomposition proceeds at a rate of $0.35 \mathrm{~nm} /$ cycle, which is higher than before the phosphate process. It appears that the presence of phosphate on the substrate surface enhances the thermal decomposition rate. Indeed, when this experiment is repeated with just a single phosphate exposure pulse (10 s TMP plasma, followed by $10 \mathrm{~s}_{2}$ plasma), again followed by 50 VTIP pulses, as in curve (b), no initial nucleation delay is observed, and the VTIP immediately starts decomposing at a rate of $0.35 \mathrm{~nm} /$ cycle.

When a similar experiment is done with TEMAV instead of VTIP, the results are remarkably different, as illustrated in Fig. 3. When pulsing TEMAV onto a blank silicon substrate at $300^{\circ} \mathrm{C}$, thermal decomposition occurs at a rate of approximately $1.0 \mathrm{~nm} /$ cycle over 20 pulses of $20 \mathrm{~s}$ TEMAV. When included in a vanadium phosphate process (consisting of TMP plasma, $\mathrm{O}_{2}$ plasma, and TEMAV exposures, repeated for 10 cycles), the growth rate is, surprisingly, slightly lower than when only pulsing TEMAV. This is incompatible with the naive idea of a CVD contribution adding to the growth rate of the total process. Moreover, when pulsing only TEMAV after having deposited vanadium phosphate, growth ceases for about five cycles before resuming (as circled by the dashed gray line in Fig. 3). This effect is repeatable: after decomposition has resumed, running 10 cycles of vanadium phosphate is again sufficient to

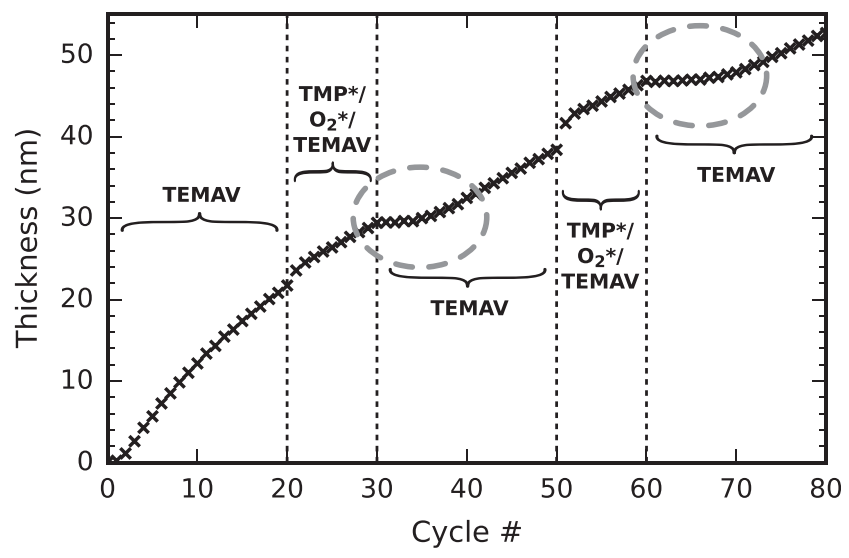

FIG. 3. Decomposition test with TEMAV at a substrate temperature of $300^{\circ} \mathrm{C}$, showing the evolution of the deposited film thickness as a function of the cycle number for a process consisting of $20 \times[20 \mathrm{~s}$ TEMAV] $-10 \times$ $\left[15 \mathrm{~s}\right.$ TMP plasma-10s $\mathrm{O}_{2}$ plasma-20s TEMAV $]-20 \times\left[\begin{array}{ll}20 \mathrm{~s} \\ \mathrm{~s}\end{array}\right.$ TEMAV $]-10 \times\left[15 \mathrm{~s}\right.$ TMP plasma $-10 \mathrm{~s} \mathrm{O}_{2}$ plasma $-20 \mathrm{~s}$ TEMAV $]-20 \times$ [20 s TEMAV]. 
temporarily inhibit the growth caused by the subsequent TEMAV exposures.

In conclusion, on a blank silicon substrate, at $300^{\circ} \mathrm{C}$, both VTIP and TEMAV decompose thermally. In the presence of phosphate covering the substrate surface, VTIP decomposes at an even higher rate, making a PE-ALD process impossible due to the CVD contribution. The decomposition of VTIP leads to a poorly controlled PE-CVD process and yields nonuniform films. However, TEMAV exhibits strikingly different behavior: in the presence of phosphate, its thermal decomposition ceases. This effect enables us to develop a PE-ALD process for vanadium phosphate using TEMAV at a substrate temperature of $300^{\circ} \mathrm{C}$, even though this temperature is significantly above the traditionally reported decomposition temperature of the precursor. Our empirical tests reveal that, as long as the phosphate step is included, no thermal decomposition takes place, resulting in a well-controlled PE-ALD process yielding high-quality films.

\section{B. Growth of vanadium phosphate}

From this point on, all depositions have been done using the [TMP plasma $-\mathrm{O}_{2}$ plasma-TEMAV] process sequence at a substrate temperature of $300{ }^{\circ} \mathrm{C}$, unless otherwise specified. In Figs. 4 and 5, pulse times of 15, 10, and $20 \mathrm{~s}$ were chosen, which will later be shown to be in a saturated region.

Figure 4 shows a growth curve measured by in situ ellipsometry during a 50-cycle deposition, revealing linear film growth at a growth rate of $0.78 \mathrm{~nm} /$ cycle with no nucleation delay. An ex situ XRR measurement of the same film after deposition is shown as an inset; the strong and nondecaying fringes indicate a high-quality, smooth film, and the associated film thickness of $39 \mathrm{~nm}$ agrees with the in situ ellipsometry measurement.

Figure 5(a) illustrates the excellent correspondence between the measured $\Psi$ and $\Delta$ angles during in situ ellipsometry and the calculated curves based on a Tauc-Lorentz optical model. By varying only the film thickness as a parameter, the measured curves are reproduced almost

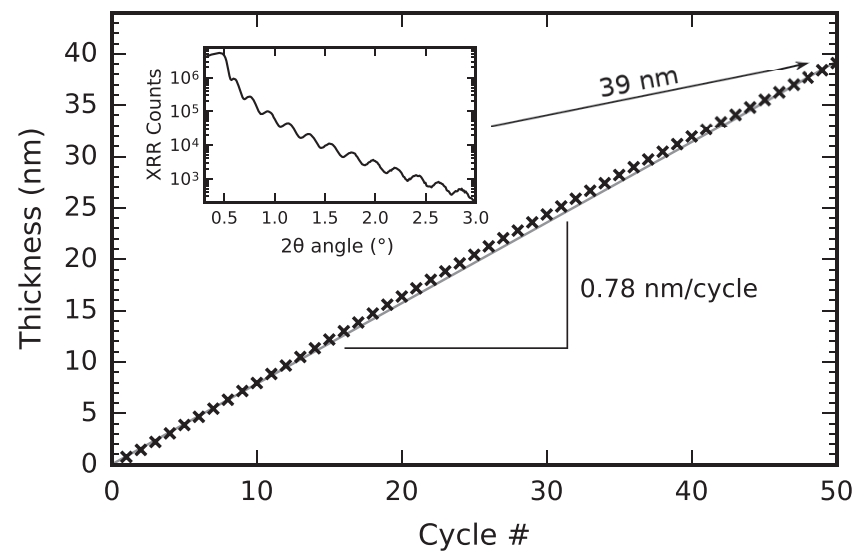

FIG. 4. Growth curve acquired by in situ ellipsometry during deposition of vanadium phosphate. The inset shows the corresponding XRR pattern after deposition, yielding a layer thickness of $39 \mathrm{~nm}$.

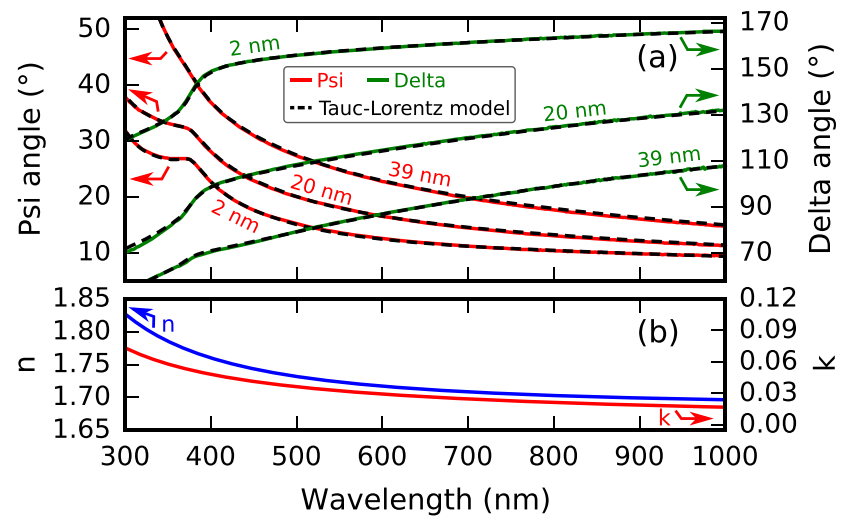

FIG. 5. (Color online) Composite plot containing (a) the evolution of the ellipsometric $\Psi$ and $\Delta$ angles during film growth, showing excellent correspondence between the measured and the calculated curves, and (b) the optical model of the as-deposited material, showing the refractive index $n$ and the absorption coefficient $k$ as a function of the wavelength (shared $\mathrm{x}$-axis).

perfectly by the calculation, giving confidence in the optical model and in the accuracy of the film thickness determination. The dispersion curve (i.e., the wavelength-dependent value of the refractive index) is shown in Fig. 5(b). It reveals that the deposited vanadium phosphate has a refractive index of 1.72 at a standard wavelength of $589 \mathrm{~nm}$.

\section{Pulse time dependence}

The saturation behavior of the process was investigated by running a series of depositions where only one of the pulse times was systematically varied, while keeping the two others constant. For each combination, a 50-cycle deposition was carried out, and the resulting sample was measured by XRR in order to determine the film thickness and density. The average growth per cycle (GPC) was calculated by dividing the film thickness by the number of cycles. The results are shown in Fig. 6. The three subplots show both the GPC and the density as a function of the TMP plasma [Fig. 6(a)], $\mathrm{O}_{2}$ plasma [Fig. 6(b)], and TEMAV [Fig. 6(c)] exposure durations.

Figure 6(a) reveals a decreasing GPC with increasing TMP plasma duration. Although this is very unexpected for an ALD process (conventionally, increasing the precursor exposure results in an increased GPC, until saturation occurs), it is not surprising when taking into account the results of the decomposition experiments. Without TMP plasma, no phosphate is present on the substrate surface, and TEMAV thermally decomposes, resulting in a high GPC and an increased film density (the decomposition product mainly consists of vanadium oxide, which is denser than vanadium phosphate).

Figure 6(b) demonstrates that the $\mathrm{O}_{2}$ plasma duration has only a small influence on the GPC (causing it to increase slightly between 2 and $10 \mathrm{~s}$ exposure) and no measurable influence on the film density (it remains constant in the same interval). Without $\mathrm{O}_{2}$ plasma [the $0 \mathrm{~s}$ point, i.e., a (TMP plasma-TEMAV) process], the process also works, albeit with a lower GPC and a significantly lower film density. It is likely that this is caused by (low-density) carbon 


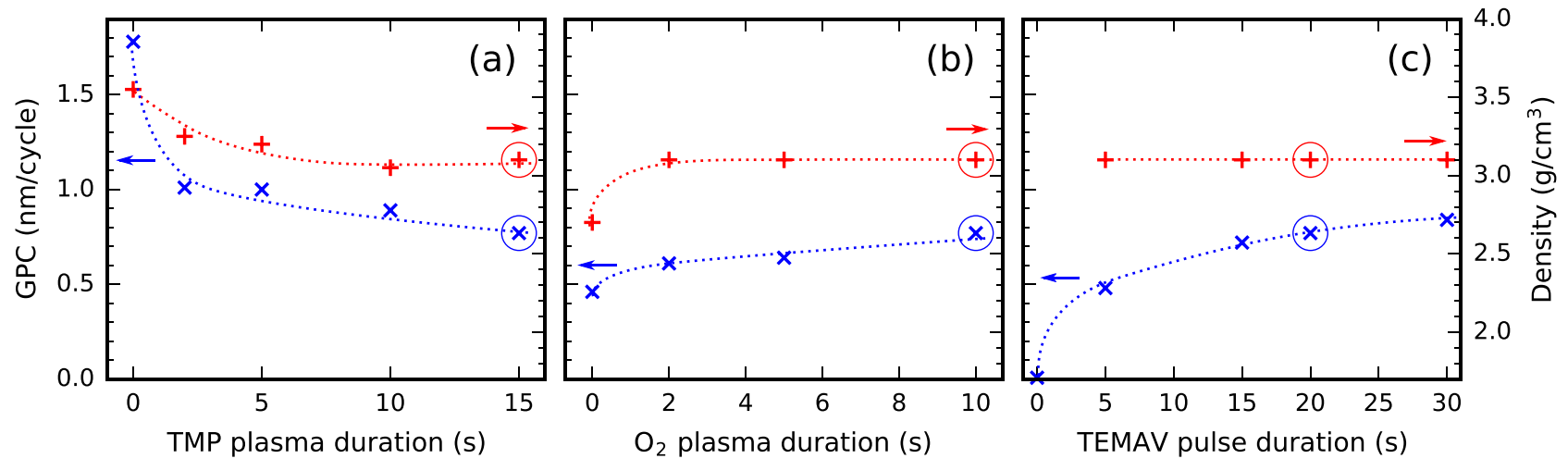

FIG. 6. (Color online) Growth per cycle (left y-axis, blue crosses) and the film density (right y-axis, red plus signs) as a function of (a) the TMP plasma duration, (b) the $\mathrm{O}_{2}$ plasma duration, and (c) the TEMAV pulse duration. The y-axes are shared. The circled points indicate the "standard" durations which were used for the nonvaried pulse times. Dashed lines are guides to the eye.

contamination, which is removed by combustion when including the $\mathrm{O}_{2}$ plasma.

Figure 6(c) resembles a typical "slow saturation" ALD curve. It confirms that we have a PE-ALD type process, and that the TEMAV precursor does not exhibit significant thermal decomposition; otherwise, the GPC would be proportional to the TEMAV pulse duration. The film density remains constant at $3.1 \mathrm{~g} / \mathrm{cm}^{3}$ and is independent of the TEMAV exposure.

\section{Temperature dependence}

The influence of the substrate temperature on the deposition process was investigated by carrying out 50 -cycle depositions between 150 and $350^{\circ} \mathrm{C}$. The pulse durations were fixed to the saturated values as shown by the circled points in Fig. 6. As in Sec. IIIC, the resulting samples were measured by XRR in order to extract the GPC and film density. The results are shown in Fig. 7.

On the low-temperature side, when the temperature decreases below approx. $200^{\circ} \mathrm{C}$, the GPC increases and the film density decreases. This can be attributed to a CVD component caused by the continuous polymerization of the TMP plasma, as was also observed in other processes using TMP

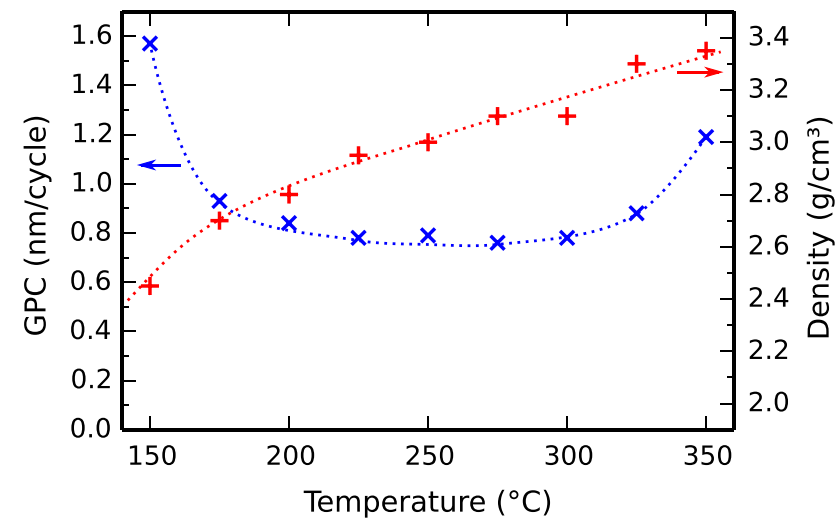

FIG. 7. (Color online) Growth per cycle (left y-axis, blue crosses) and the film density (right y-axis, red plus signs) of the vanadium phosphate films as a function of the substrate temperature between 150 and $350^{\circ} \mathrm{C}$. Dashed lines are guides to the eye. plasma. ${ }^{12,13,17,18}$ The resulting films are then phosphorusrich, resulting in a decreased density.

On the high-temperature side (above $300^{\circ} \mathrm{C}$ ), the GPC and density increase with temperature. We attribute this to the thermal decomposition of TEMAV, resulting in an extra contribution of a (higher-density) vanadium oxide decomposition product.

In the temperature region between 200 and $300^{\circ} \mathrm{C}$, the GPC is observed to remain constant. Although this is commonly referred to as the "ALD temperature window," this does not explain why the film density increases with temperature; in a classical temperature window, the density should remain constant. We suppose that it is rather a combination of two effects: on the one hand, the GPC may decrease with temperature due to diminishing CVD contributions from the TMP plasma, while on the other hand, it may increase with temperature due to the increased reactivity of the TEMAV precursor. These effects cancel out each other when it comes to the GPC. For the film density, however, this is not necessarily the case; decreasing contributions of the TMP plasma polymerization result in an increasing density, and increasing amounts of vanadium being incorporated may also result in an increasing density, the combined effect being an increasing density with temperature.

\section{E. Film composition}

As-deposited films were analyzed by XPS and ERD in order to investigate their chemical composition. They were grown at a substrate temperature of $300^{\circ} \mathrm{C}$, using the same pulse durations as in Sec. IIID. The XPS analysis is shown in Fig. 8. The survey spectra reveal the presence of vanadium, phosphorus, and oxygen. The surface spectrum additionally shows the presence of carbon and nitrogen, which most likely originates from environmental contamination; after sputter erosion, their signals disappear, which implies that they do not occur in the "bulk" of the film. No silicon signal is observed, proving that the silicon substrate is fully covered by the vanadium phosphate film.

After calibrating the energy spectrum so that the peak position of $\mathrm{C} 1 \mathrm{~s}$ (surface carbon) occurs at a binding energy of $284.8 \mathrm{eV}$, the detailed spectra in Fig. 8 reveal $\mathrm{P}$ 


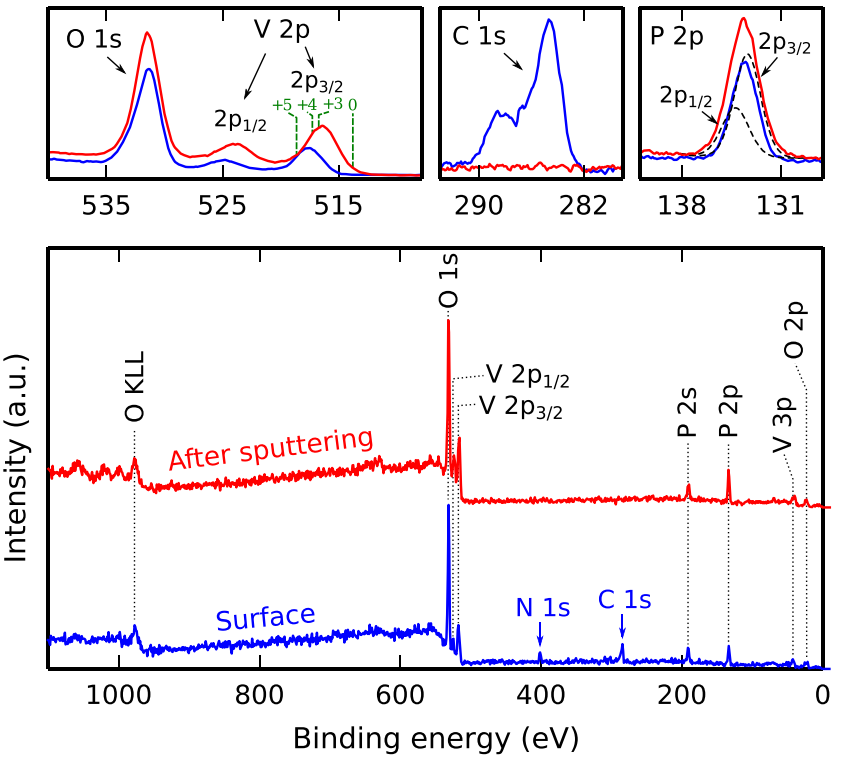

FIG. 8. (Color online) XPS analysis of the as-deposited vanadium phosphate. Survey scans and detailed scans were acquired on the film surface (lower spectrum) and after argon sputtering (upper spectrum). Possible vanadium $2 \mathrm{p}_{3 / 2}$ oxidation states are labeled by the dashed vertical lines in the detailed scan.

$2 \mathrm{p}_{1 / 2}, \mathrm{P} 2 \mathrm{p}_{3 / 2}, \mathrm{~V} 2 \mathrm{p}_{1 / 2}, \mathrm{~V} 2 \mathrm{p}_{3 / 2}$, and $\mathrm{O} 1 \mathrm{~s}$ peak positions of resp. 134.3, 133.4, 524.8, 517.5, and 531.3 eV. After sputter erosion, the peak positions of $\mathrm{V} 2 \mathrm{p}_{1 / 2}$ and $\mathrm{V} 2 \mathrm{p}_{3 / 2}$ shift to resp. 523.9 and $516.4 \mathrm{eV}$, while the phosphorus and oxygen line positions remain unchanged. The phosphorus and oxygen core levels are compatible with a phosphate material, but provide little information on the exact kind of phosphate. $^{37,38}$ The vanadium core levels do yield important information: as the distance between $\mathrm{O} 1 \mathrm{~s}$ and $\mathrm{V} 2 \mathrm{p}_{3 / 2}$ is tightly correlated with the oxidation state of vanadium, ${ }^{39}$ the observed $\mathrm{V} 2 \mathrm{p}_{3 / 2}$ peak positions reveal a mixture of $\mathrm{V}^{5+}$ and $\mathrm{V}^{4+}$ on the film surface, and mainly $\mathrm{V}^{3+}$ in the bulk of the film. The vanadium peak positions in the bulk of the film did not significantly shift upon further sputter erosion, suggesting that the measured oxidation states were not significantly influenced by the argon sputtering process itself.

Although XPS can be used for quantification, uncertainties are typically quite large; therefore, we opted to use ERD as a more accurate technique to measure the film stoichiometry, with the added advantage that hydrogen can be detected as a possible impurity element. The ERD depth profile of a $36 \mathrm{~nm}$ film is shown in Fig. 9. It should be noted that the depth scale on the upper $\mathrm{x}$-axis of the figure is only approximate, as the true depth scale (lower $\mathrm{x}$-axis) stems from atomic energy loss which is proportional to the total areal density; a rough conversion was provided by comparison with the XRR-measured film thickness in order to aid interpretation. By integrating the amounts of $\mathrm{V}, \mathrm{P}, \mathrm{O}$, and $\mathrm{H}$ over the film thickness, an average stoichiometry of $\mathrm{V}_{1.1} \mathrm{PO}_{4.3}$ is found with a $3 \%$ hydrogen impurity and zero carbon (within the detection limit of $0.1 \%$ ). This makes it likely that the vanadium is indeed mainly in a $3+$ oxidation state, given the triple negative charge of the $\mathrm{PO}_{4}^{3-}$ anion.

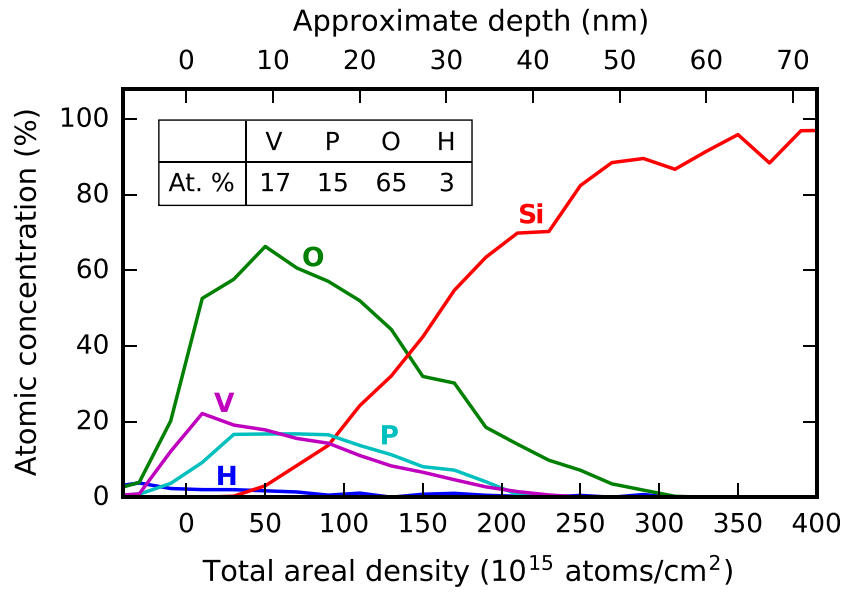

FIG. 9. (Color online) ERD depth profile measured on a $36 \mathrm{~nm}$ as-deposited vanadium phosphate film, showing the atomic concentrations of elements as a function of the areal density. An approximate depth scale is provided on the secondary $\mathrm{x}$-axis. The table inset shows integrated atomic percentages representing the average film composition.

\section{F. Crystallinity}

The crystalline structure of the deposited film was investigated by XRD. Full XRD scans (between $15^{\circ}$ and $55^{\circ}$ in $2 \theta$ angle) were acquired before and after annealing, and are shown in Fig. 10(b). The annealing process took place in a helium atmosphere by applying a linear temperature ramp, starting at room temperature and ramping to $950{ }^{\circ} \mathrm{C}$ at a rate of $10^{\circ} \mathrm{C} / \mathrm{min}$. During annealing, XRD patterns were acquired using a fixed position sensitive detector with a $2 \theta$ window of $16^{\circ}-34^{\circ}$, allowing in situ observation of phase transitions. The resulting plot, showing both the XRD intensity and the temperature as a function of the elapsed time, is given in Fig. 10(a).

The as-deposited film does not show any diffraction peaks and is thus amorphous. The film stays amorphous until heated to a fairly high temperature of $900^{\circ} \mathrm{C}$, where the sudden formation of crystalline $\mathrm{VPO}_{4}$ (orthorhombic; JCPDS No. 76-2023) appears by its (110) reflection at $20.4^{\circ}$. In the full XRD scan, the (200), (112), (220), and (202) reflections are additionally visible at $34.3^{\circ}, 35.2^{\circ}, 41.6^{\circ}$, and $45.1^{\circ}$, respectively. Given that the intensity ratios differ from the powder diffraction data and that many additional calculated reflections are not observed, it is likely that there is a high degree of preferential orientation.

\section{G. Electrochemical characterization}

\section{Cyclic voltammetry}

The as-deposited material was tested as a lithium-ion battery electrode. A test cell was assembled using, as the working electrode, a $35 \mathrm{~nm}$ vanadium phosphate film deposited on a planar Pt-coated silicon substrate. An open-circuit potential (OCP) of $3.12 \mathrm{~V}$ was measured. It was then lithiated by cyclic voltammetry: starting from the OCP, the potential was decreased at a scan rate of $-1 \mathrm{mV} / \mathrm{s}$, until a potential of $0.5 \mathrm{~V}$ was reached. This was followed by delithiation through a reversal of the scanning direction up to 4.3 V. The resulting CV pattern is shown in Fig. 11(a). 

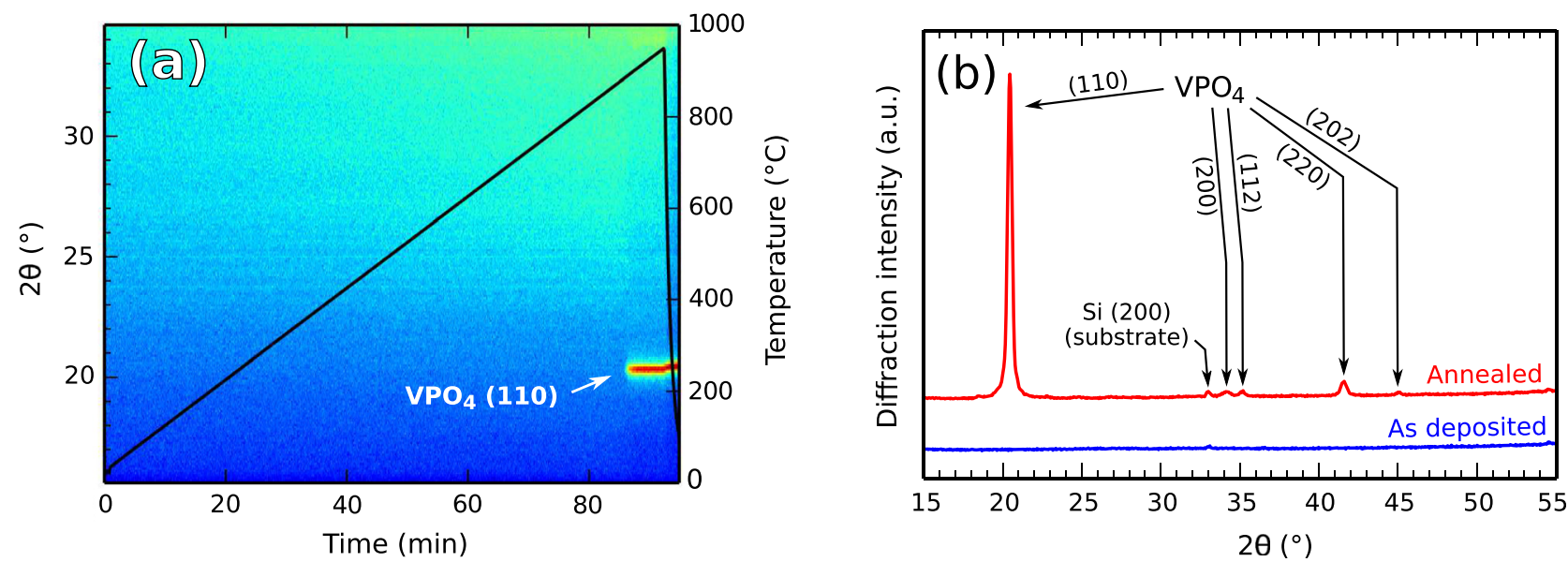

FIG. 10. (Color online) In situ X-ray diffraction during annealing of the as-deposited vanadium phosphate in a helium atmosphere. (a) Color plot showing the evolution of the XRD pattern (in color intensity, left X-axis) and temperature (black solid line, right y-axis) as a function of time; (b) conventional XRD patterns acquired at room temperature, before and after annealing.

Between the OCP and approximately $1 \mathrm{~V}$, almost no current flow is observed, implying that almost no lithium ions are inserted. Between 1 and $0.5 \mathrm{~V}$, however, a large and sharply peaked reduction reaction is observed, consisting of a doublet with the first peak (at $0.75 \mathrm{~V}$ ) corresponding to a charge insertion of $-3.6 \mu \mathrm{Ah} / \mathrm{cm}^{2}$, and the second one (at $0.65 \mathrm{~V}$ ) to a charge insertion of $-4.6 \mu \mathrm{A} \mathrm{h} / \mathrm{cm}^{2}$, with a total inserted charge of $-8.2 \mu \mathrm{Ah} / \mathrm{cm}^{2}$. Assuming that the film consists of $\mathrm{VPO}_{4}$ (which is close to the stoichiometry measured by ERD), with a molar mass of $146 \mathrm{~g} / \mathrm{mol}$, a density of $3.1 \mathrm{~g} /$ $\mathrm{cm}^{3}$, and a thickness of $35 \mathrm{~nm}$, it requires a charge of $2.0 \mu \mathrm{A} \mathrm{h} / \mathrm{cm}^{2}$ to insert one lithium ion. The first peak can likely be attributed to the intercalation of $\mathrm{Li}^{+}$in $\mathrm{VPO}_{4}$, reducing $\mathrm{V}(+\mathrm{III})$ to $\mathrm{V}(+\mathrm{II})$

$$
\mathrm{VPO}_{4}+\mathrm{Li}^{+}+\mathrm{e}^{-} \rightarrow \mathrm{LiVPO}_{4} .
$$

This reaction consumes a charge of $2.0 \mu \mathrm{A} \mathrm{h} / \mathrm{cm}^{2}$, while $3.6 \mu \mathrm{A} \mathrm{h} / \mathrm{cm}^{2}$ was measured. We thus hypothesize that, in addition to the conversion of $\mathrm{V}^{3+}$ to $\mathrm{V}^{2+}$, an additional charge of $1.6 \mu \mathrm{Ah} / \mathrm{cm}^{2}$ was consumed in the build-up of a solid-electrolyte interphase (SEI). ${ }^{40}$ The second peak is attributed to a conversion reaction where vanadium is reduced from $\mathrm{V}(+\mathrm{II})$ to $\mathrm{V}(0)$ (i.e., vanadium metal)

$$
\mathrm{LiVPO}_{4}+2 \mathrm{Li}^{+}+2 \mathrm{e}^{-} \rightarrow \mathrm{Li}_{3} \mathrm{PO}_{4}+\mathrm{V} .
$$

The above reaction consumes a charge of $4.0 \mu \mathrm{Ah} / \mathrm{cm}^{2}$, while $4.6 \mu \mathrm{Ah} / \mathrm{cm}^{2}$ was measured; the small difference can either be attributed to measurement inaccuracies or to an extra SEI contribution.

Upon reoxidation to $4.3 \mathrm{~V}$, a total charge of $+5.7 \mu \mathrm{Ah} /$ $\mathrm{cm}^{2}$ is extracted. This is close to the expected charge $\left(+6.0 \mu \mathrm{A} \mathrm{h} / \mathrm{cm}^{2}\right)$ associated with a full reoxidation of $\mathrm{V}(0)$ to $\mathrm{V}(+\mathrm{III})^{32}$

$$
\mathrm{Li}_{3} \mathrm{PO}_{4}+\mathrm{V} \rightarrow \mathrm{VPO}_{4}+3 \mathrm{Li}^{+}+3 \mathrm{e}^{-} .
$$

Repeated cycling between 0.5 and $4.3 \mathrm{~V}$, as shown in Fig. 11(b), yields charges of $-6.8,+5.9,-6.6,+5.8,-6.4$, and $+5.7 \mu \mathrm{A} \mathrm{h} / \mathrm{cm}^{2}$. Perhaps due to incomplete SEI build-up, or due to some other electron-consuming side reaction, the cathodic capacity remains systematically larger than the anodic capacity. Figure 11(c) shows subsequent CV cycling on the same electrode within a narrower potential range
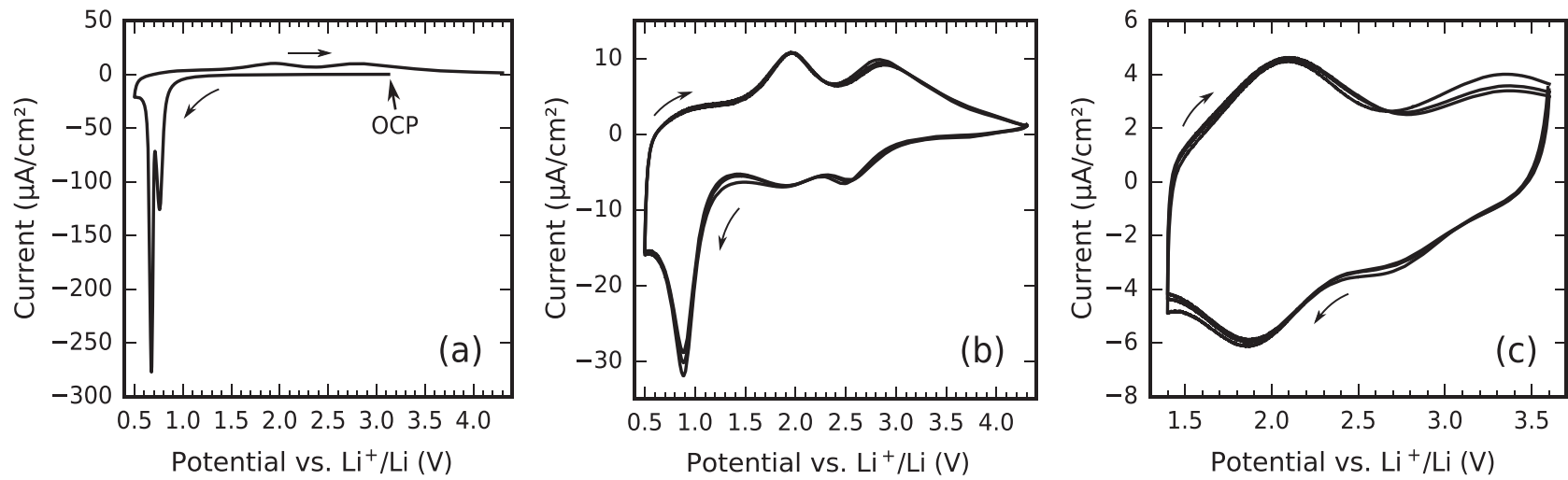

FIG. 11. Cyclic voltammetry experiments showing (a) the initial lithiation of a $35 \mathrm{~nm}$ as-deposited vanadium phosphate film; (b) subsequent cycling between 0.5 and $4.3 \mathrm{~V}$; and (c) subsequent cycling between 1.4 and $3.6 \mathrm{~V}$. All patterns were acquired at a scan rate of $1 \mathrm{mV} / \mathrm{s}$. The scanning directions are indicated by arrows. 
between 1.4 and $3.6 \mathrm{~V}$. This results in charges of -2.0 , $+2.0,-2.0,+2.0,-2.0$, and $+1.9 \mu \mathrm{Ah} / \mathrm{cm}^{2}$; while the capacity is lower (approximately one $\mathrm{Li}^{+}$per unit of $\mathrm{VPO}_{4}$ is inserted/extracted, compared to three in the extended potential range), the difference between the cathodic and anodic capacities is now much smaller. Rather than having full conversion reactions between $\mathrm{V}(+\mathrm{III})$ and $\mathrm{V}(0)$, we hypothesize that the cycling is now restricted between the $\mathrm{V}(+\mathrm{III})$ and $\mathrm{V}(+\mathrm{II})$ oxidation states in an intercalation-type reaction

$$
\mathrm{VPO}_{4}+\mathrm{Li}^{+}+\mathrm{e}^{-} \leftrightarrow \mathrm{LiVPO}_{4} .
$$

\section{Charge/discharge cycling}

After initial lithiation [i.e., the reaction shown in Fig. 11(a)], the electrodes were subjected to repeated constantcurrent charge/discharge cycling, as shown in Fig. 12. These tests were performed in two potential regions: the restricted range between 1.4 and 3.6 V, used for Figs. 12(a)-12(c), and the extended range between 0.5 and $4.3 \mathrm{~V}$, used for Figs. 12(d)-12(f).

In the restricted potential range, the charge/discharge curves [Fig. 12(a)] and the capacity evolution plot [Fig. 12(b)] were acquired at constant charge/discharge currents of $\pm 2.4 \mu \mathrm{A} / \mathrm{cm}^{2}$ (positive for charge, negative for discharge). This yielded an accessible capacity of $2.2 \mu \mathrm{Ah} / \mathrm{cm}^{2}$. Normalized to the film thickness, this corresponds to a volumetric capacity of $630 \mathrm{~mA} \mathrm{~h} / \mathrm{cm}^{3}$, or taking into account the density of the material, to a specific capacity of 200 $\mathrm{mAh} / \mathrm{g}$. Figure 12(b) reveals an average coulombic efficiency of $98.9 \%$ and a capacity degradation of only $0.7 \%$ over 100 cycles. Assuming a $1 \mathrm{C}$ current of $2.2 \mu \mathrm{A} / \mathrm{cm}^{2}$ (corresponding to the current necessary to reach the measured capacity in $1 \mathrm{~h}$ ), Fig. 12(c) shows the accessible capacity measured by charge/discharge cycling at multiples of the $1 \mathrm{C}$ current up to $100 \mathrm{C}$. The electrode shows an excellent rate capability, still retaining over $60 \%$ of its original capacity at a rate of $100 \mathrm{C}$.

In the extended potential range, the charge/discharge curves [Fig. 12(d)] and the capacity evolution plot [Fig. 12(e)] were acquired at a charge/discharge current of $\pm 5.7 \mu \mathrm{A} / \mathrm{cm}^{2}$. This resulted in a measured capacity of $6.7 \mu \mathrm{Ah} / \mathrm{cm}^{2}$, i.e., a volumetric capacity of $1.9 \mathrm{Ah} / \mathrm{cm}^{3}$ or a gravimetric capacity of $620 \mathrm{~mA} \mathrm{~h} / \mathrm{g}$. Although impressively high, this capacity is only retained for 40 cycles, as demonstrated in Fig. 12(e). Upon further cycling, the capacity starts degrading steadily and reaches $4.8 \mu \mathrm{Ah} / \mathrm{cm}^{2}$ after 120 cycles (i.e., a $28 \%$ loss compared to the original capacity), whereafter it seems to stabilize again. This rather poor cyclability is typical for conversion-type reactions, and similar behavior has been reported in literature for $\mathrm{VOPO}_{4}$ nanosheet anodes. ${ }^{33}$ The coulombic efficiency, however, remains close to $100 \%$ (with an average value of $99.6 \%$ ) throughout the entire cycling experiment. The rate testing results, based on a $1 \mathrm{C}$ current of $4.8 \mu \mathrm{A} / \mathrm{cm}^{2}$ (corresponding to the final measured
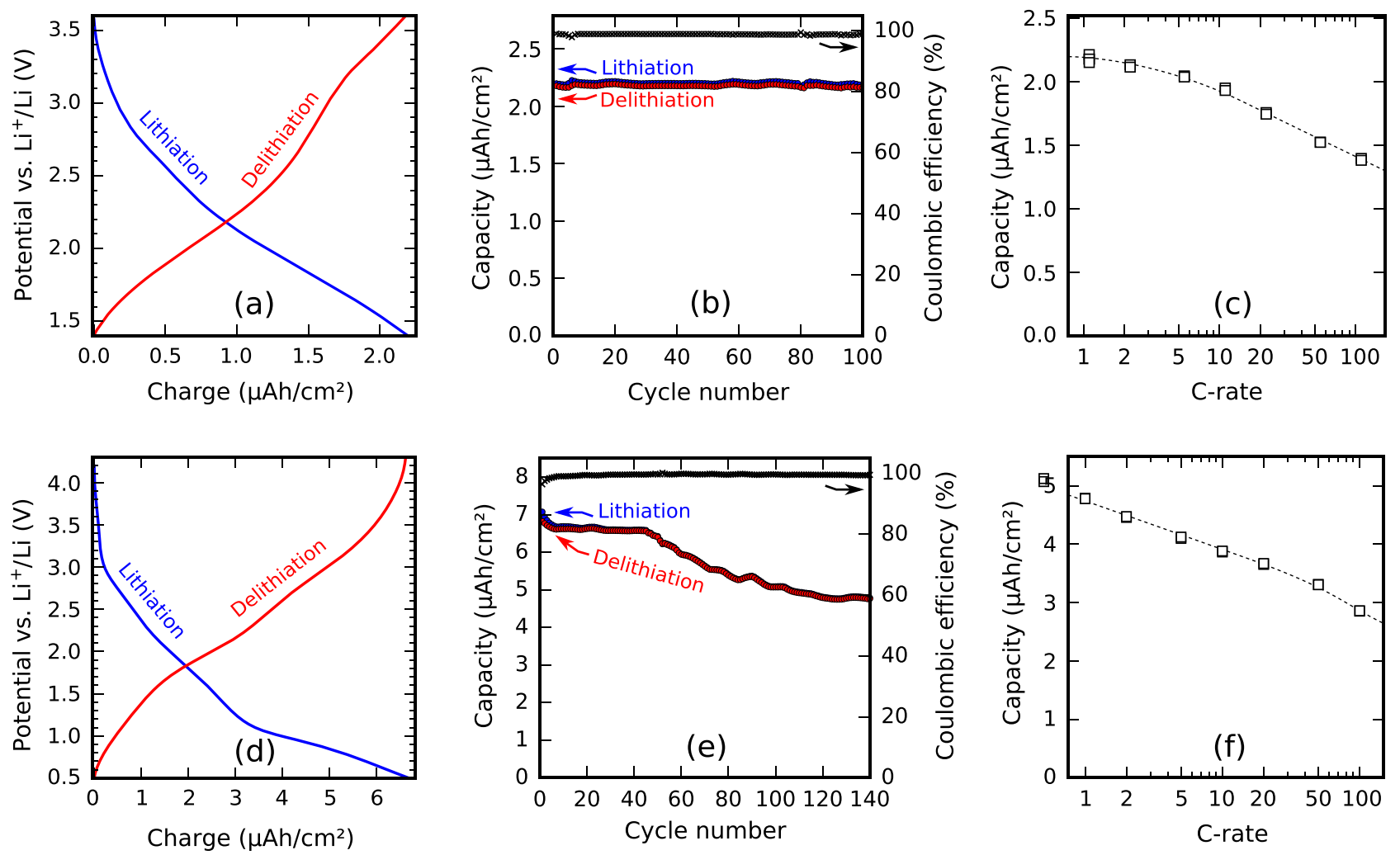

FIg. 12. (Color online) Constant-current charge/discharge cycling of a $35 \mathrm{~nm}$ vanadium phosphate film between 1.4 and $3.6 \mathrm{~V}$ [(a)-(c)] and between 0.5 and $4.3 \mathrm{~V}[(\mathrm{~d})-(\mathrm{f})]$, showing [(a) and (d)] the potential as a function of the inserted/extracted charge; [(b) and (e)] the evolution of the measured capacity (left $\mathrm{y}-$ axis) and coulombic efficiency (right $\mathrm{y}$-axis) over multiple charge/discharge cycles at approximately $1 \mathrm{C}$; and [(c) and (f)] the available capacity as a function of the C-rate. 
capacity), are shown in Fig. 12(f). Similar to the restricted potential range, the rate capability is excellent, with $60 \%$ of the $1 \mathrm{C}$ capacity still being available at a rate of $100 \mathrm{C}$.

Although a quantitative comparison with earlier reports on amorphous vanadium phosphate electrodes by Sakurai et al. ${ }^{30,31}$ is not possible- they focused on $\mathrm{V}_{2} \mathrm{O}_{5}-\mathrm{P}_{2} \mathrm{O}_{5}$ mixtures with molar ratios between $60 \%$ and $95 \% \mathrm{~V}_{2} \mathrm{O}_{5}$, while our as-deposited material has only about $52 \% \mathrm{~V}_{2} \mathrm{O}_{5}$ based on its measured stoichiometry; furthermore, they cycled in a different potential region of $2.0-3.5 \mathrm{~V}$ and used a different electrolyte-some interesting similarities can be noted. The good capacity retention upon repeated cycling (which has been attributed to the presence of phosphorus) is also confirmed here, at least when cycling in the restricted potential range. Compared to the reversible uptake of $0.27 \mathrm{Li} / \mathrm{V}$ measured by Sakurai et al. ${ }^{30}$ for $60 \% \mathrm{~V}_{2} \mathrm{O}_{5}$, we find a much higher value of $1.1 \mathrm{Li} / \mathrm{V}$; this may be due to our lower potential cut-off ( $1.4 \mathrm{~V}$, versus $2.0 \mathrm{~V}$ as chosen by Sakurai et al.) or due to the beneficial effect of using a nanoscale thin film rather than a powder mixture.

In the extended potential region (i.e., making use of the full conversion reaction), our results can be compared to those of Zhang et al ${ }^{33}$ who started from $\mathrm{VOPO}_{4}$ which was converted to $\mathrm{VPO}_{4}$ in an initial reduction reaction, making the resulting electrode composition similar to ours. They measured high initial capacities equivalent to approximately $3 \mathrm{Li} / \mathrm{V}$, which however degraded by more than $50 \%$ after about 40 charge/discharge cycles. This is very similar to our results. While cycling to low potentials induces full conversion reactions and thus yields a high capacity, it also induces electrode degradation. To prevent this, the potential needs to be restricted to remain above $1.4 \mathrm{~V}$.

\section{CONCLUSIONS}

Using pulses of TMP plasma, $\mathrm{O}_{2}$ plasma, and TEMAV vapor, a PE-ALD process for vanadium phosphate was developed, which worked optimally at a substrate temperature of $300^{\circ} \mathrm{C}$. Given the need for a high substrate temperature to avoid CVD contributions by the TMP plasma, the thermal decomposition of VTIP and TEMAV was investigated. Although both VTIP and TEMAV showed thermal decomposition, TEMAV had the unique property of not decomposing on a substrate surface when phosphate was present. This made a PE-ALD phosphate process possible. The process showed linear growth at a rate of $0.78 \mathrm{~nm} / \mathrm{cycle}$, and slow saturation was observed for the TEMAV pulse. The deposited film density continuously increased with a substrate temperature, having a value of $3.1 \mathrm{~g} / \mathrm{cm}^{3}$ at $300^{\circ} \mathrm{C}$, while the GPC strongly increased below $200^{\circ} \mathrm{C}$ and above $300^{\circ} \mathrm{C}$ due to TMP plasma polymerization and thermal decomposition of TEMAV, respectively. The deposited material consisted of $\mathrm{V}_{1.1} \mathrm{PO}_{4.3}$ with $3 \%$ hydrogen and zero carbon, as measured by ERD, and XPS revealed that the vanadium was mainly in a $3+$ oxidation state. The material was amorphous as-deposited, but could be crystallized to $\mathrm{VPO}_{4}$ by postdeposition annealing to $900^{\circ} \mathrm{C}$ in a helium atmosphere. The as-deposited material could be electrochemically lithiated and delithiated, showing a volumetric capacity of $630 \mathrm{mAh} / \mathrm{cm}^{3}$ between 1.4 and $3.6 \mathrm{~V}$, and a remarkably high $1.9 \mathrm{Ah} / \mathrm{cm}^{3}$ between 0.5 and $4.3 \mathrm{~V}$ versus $\mathrm{Li}^{+} / \mathrm{Li}$. However, while long-term cycling in the former potential region was possible with almost no capacity degradation ( $0.7 \%$ over 100 cycles), in the latter region, the capacity started degrading after 40 charge/discharge cycles, resulting in a $28 \%$ capacity loss after 140 cycles. In both regions, the electrode had a high coulombic efficiency and an excellent rate capability, still maintaining over $60 \%$ of its $1 \mathrm{C}$ capacity at a rate of $100 \mathrm{C}$.

\section{ACKNOWLEDGMENTS}

The authors are grateful to the FWO Vlaanderen for providing Thomas Dobbelaere with financial support through the mandate of Aspirant. They also acknowledge the financial support from the UGENT-GOA-01G01513, Hercules AUGE/ 09/014, IWT-SBO SOSLion, and FWO-Vlaanderen projects.

${ }^{1}$ R. W. Johnson, A. Hultqvist, and S. F. Bent, Mater. Today 17, 236 (2014).

${ }^{2}$ V. Miikkulainen, M. Leskelä, M. Ritala, and R. L. Puurunen, J. Appl. Phys. 113, 021301 (2013).

${ }^{3}$ M. Nieminen, L. Niinistö, and R. Lappalainen, Microchim. Acta 119, 13 (1995).

${ }^{4}$ M. Tiitta, E. Nykänen, P. Soininen, L. Niinistö, M. Leskelä, and R. Lappalainen, Mater. Res. Bull. 33, 1315 (1998).

${ }^{5}$ M. Putkonen, T. Sajavaara, P. Rahkila, L. Xu, S. Cheng, L. Niinistö, and H. J. Whitlow, Thin Solid Films 517, 5819 (2009).

${ }^{6}$ M. K. Wiedmann, D. H. K. Jackson, Y. J. Pagan-Torres, E. Cho, J. A. Dumesic, and T. F. Kuech, J. Vac. Sci. Technol., A 30, 01 A134 (2012).

${ }^{7}$ J. Hämäläinen, J. Holopainen, F. Munnik, M. Heikkilä, M. Ritala, and M. Leskelä, J. Phys. Chem. C 116, 5920 (2012).

${ }^{8}$ S. Knohl et al., ACS Appl. Mater. Interfaces 5, 6161 (2013).

${ }^{9}$ J. Liu, Y. Tang, B. Xiao, T.-K. Sham, R. Li, and X. Sun, RSC Adv. 3, 4492 (2013).

${ }^{10}$ A. R. Ananda Sagari, J. Malm, M. Laitinen, P. Rahkila, M. Hongqiang, M. Putkonen, M. Karppinen, H. J. Whitlow, and T. Sajavaara, Thin Solid Films 531, 26 (2013).

${ }^{11}$ H. H. Sønsteby, E. Østreng, H. Fjellvåg, and O. Nilsen, Chem. Vap. Deposition 20, 269 (2014).

${ }^{12}$ T. Dobbelaere, A. K. Roy, P. Vereecken, and C. Detavernier, Chem. Mater. 26, 6863 (2014).

${ }^{13}$ T. Dobbelaere, M. Minjauw, T. Ahmad, P. M. Vereecken, and C. Detavernier, J. Non-Cryst. Solids 444, 43 (2016).

${ }^{14}$ K. B. Gandrud, A. Pettersen, O. Nilsen, and H. Fjellvåg, J. Mater. Chem. A 1, 9054 (2013).

${ }^{15}$ J. Liu, M. N. Banis, Q. Sun, A. Lushington, R. Li, T.-K. Sham, and X. Sun, Adv. Mater. 26, 6472 (2014)

${ }^{16}$ J. Liu, B. Xiao, M. N. Banis, R. Li, T.-K. Sham, and X. Sun, Electrochim. Acta 162, 275 (2015)

${ }^{17}$ T. Dobbelaere, F. Mattelaer, J. Dendooven, P. Vereecken, and C. Detavernier, Chem. Mater. 28, 3435 (2016).

${ }^{18}$ T. Dobbelaere, F. Mattelaer, A. K. Roy, P. Vereecken, and C. Detavernier, J. Mater. Chem. A 5, 330 (2017).

${ }^{19}$ J. Hämäläinen, J. Holopainen, F. Munnik, T. Hatanpää, M. Heikkilä, M. Ritala, and M. Leskelä, J. Electrochem. Soc. 159, A259 (2012).

${ }^{20}$ A. C. Kozen, A. J. Pearse, C.-F. Lin, M. Noked, and G. W. Rubloff, Chem. Mater. 27, 5324 (2015).

${ }^{21}$ M. Nisula, Y. Shindo, H. Koga, and M. Karppinen, Chem. Mater. 27, 6987 (2015)

${ }^{22}$ S. Shibata, J. Electrochem. Soc. 163, A2555 (2016).

${ }^{23}$ J. Musschoot, D. Deduytsche, H. Poelman, J. Haemers, R. L. V. Meirhaeghe, S. V. d. Berghe, and C. Detavernier, J. Electrochem. Soc. 156, P122 (2009).

${ }^{24}$ G. Rampelberg, M. Schaekers, K. Martens, Q. Xie, D. Deduytsche, B. De Schutter, N. Blasco, J. Kittl, and C. Detavernier, Appl. Phys. Lett. 98, 162902 (2011). 
${ }^{25}$ T. Blanquart et al., RSC Adv. 3, 1179 (2012).

${ }^{26}$ V. E. Strempel, D. Löffler, J. Kröhnert, K. Skorupska, B. Johnson, R. N. d'Alnoncourt, M. Driess, and F. Rosowski, J. Vac. Sci. Technol., A 34, $01 \mathrm{~A} 135$ (2015).

${ }^{27}$ N. Böckenfeld and A. Balducci, J. Power Sources 235, 265 (2013).

${ }^{28}$ M. Y. Saïdi, J. Barker, H. Huang, J. L. Swoyer, and G. Adamson, J. Power Sources 119-121, 266 (2003).

${ }^{29}$ T. Pagnier, M. Fouletier, and J. L. Souquet, Solid State Ionics 9-10, 649 (1983).

${ }^{30}$ Y. Sakurai, S. Okada, J. Yamaki, and T. Okada, J. Power Sources 20, 173 (1987).

${ }^{31}$ Y. Sakurai and J.-i. Yamaki, J. Electrochem. Soc. 135, 791 (1988).

${ }^{32}$ M. M. Ren, Z. Zhou, and X. P. Gao, J. Appl. Electrochem. 40, 209 (2010).
${ }^{33}$ B. Zhang, Y.-d. Han, J.-c. Zheng, J.-f. Zhang, C. Shen, L. Ming, X.-b. Yuan, and H. Li, Chem. Commun. 50, 11132 (2014).

${ }^{34}$ Y. Zhang, X. J. Zhang, Q. Tang, D. H. Wu, and Z. Zhou, J. Alloys Compd. 522, 167 (2012).

${ }^{35}$ W. Knaepen, C. Detavernier, R. L. Van Meirhaeghe, J. Jordan Sweet, and C. Lavoie, Thin Solid Films 516, 4946 (2008).

${ }^{36}$ W. Knaepen, S. Gaudet, C. Detavernier, R. L. V. Meirhaeghe, J. J. Sweet, and C. Lavoie, J. Appl. Phys. 105, 083532 (2009).

${ }^{37}$ P. M. A. Sherwood, Surf. Sci. Spectra 9, 62 (2002).

${ }^{38}$ K. J. Gaskell, M. M. Smith, and P. M. A. Sherwood, J. Vac. Sci. Technol., A 22, 1331 (2004).

${ }^{39}$ G. Silversmit, D. Depla, H. Poelman, G. B. Marin, and R. De Gryse, J. Electron Spectrosc. Relat. Phenom. 135, 167 (2004).

${ }^{40}$ P. Verma, P. Maire, and P. Novák, Electrochim. Acta 55, 6332 (2010). 